\title{
Construction of dopamine sensors by using fluorescent ribonucleopeptide complexes.
}

\author{
$\operatorname{AUTHOR}(\mathrm{S}):$ \\ Liew, Fong Fong; Hasegawa, Tetsuya; Fukuda, \\ Masatora; Nakata, Eiji; Morii, Takashi
}

\section{CITATION:}

Liew, Fong Fong ...[et al]. Construction of dopamine sensors by using fluorescent ribonucleopeptide complexes.. Bioorganic \& medicinal chemistry 2011, 19(15): 4473-4481

\section{ISSUE DATE:}

2011-08-01

URL:

http://hdl.handle.net/2433/147155

\section{RIGHT:}

(C) 2011 Elsevier Ltd.; This is not the published version. Please cite only the published version.; この論文は出版社版でありません。引用の際に は出版社版をご確認ご利用ください。 


\section{Graphical Abstract}

To create your abstract, type over the instructions in the template box below.

Fonts or abstract dimensions should not be changed or altered.

\section{Construction of Dopamine Sensors by Using} Fluorescent Ribonucleopeptide Complexes

Leave this area blank for abstract info.

Liew Fong Fong, ${ }^{a}$ Tetsuya Hasegawa, ${ }^{a}$ Masatora Fukuda, ${ }^{a}$ Eiji Nakata ${ }^{\mathrm{a}}$ and Takashi Morii ${ }^{\mathrm{a}, \mathrm{b}}$

${ }^{\mathrm{a}}$ Institute of Advanced Energy, Kyoto University, ${ }^{\mathrm{b}} \mathrm{CREST}$, JST, Uji, Kyoto 611-0011, Japan

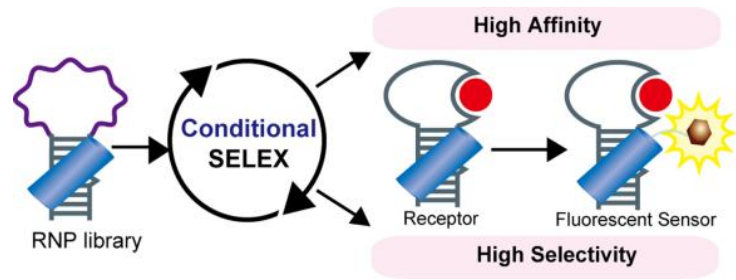




\title{
Bioorganic \& Medicinal Chemistry \\ journal homepage: www.elsevier.com
}

\section{Construction of Dopamine Sensors by Using Fluorescent Ribonucleopeptide Complexes}

\author{
Liew Fong Fong, ${ }^{a}$ Tetsuya Hasegawa, ${ }^{\mathrm{a}}$ Masatora Fukuda, ${ }^{\mathrm{a}}$ Eiji Nakata ${ }^{\mathrm{a}}$ and Takashi Morii ${ }^{\mathrm{a}, \mathrm{b}}$ * \\ ${ }^{a}$ Institute of Advanced Energy, Kyoto University, Kyoto 611-0011, Japan \\ ${ }^{b}$ CREST, JST, Uji, Kyoto 611-0011, Japan
}

\section{ARTICLE INFO}

\section{Article history}

Received

Received in revised form

Accepted

Available online

\section{Keywords:}

in vitro selection

fluorescent sensor

ribonucleopeptide

dopamine

receptor

\section{ABSTRACT}

A facile strategy of stepwise molding of a ribonucleopeptide (RNP) complex affords fluorescent RNP sensors with selective dopamine recognition. In vitro selection of a RNA-derived RNP library, a complex of the Rev peptide and its binding site Rev Responsive Element (RRE) RNA appended with random nucleotides in variable lengths, afforded RNP receptors specific for dopamine. The modular structure of the RNP receptor enables conversion of dopamine-binding RNP receptors to fluorescent dopamine sensors. Application of conditional selection schemes, such as the variation of salt concentrations and application of a counter-selection step by using a competitor ligand norepinephrine resulted in isolation of RNP receptors with defined dopaminebinding characteristics. Increasing the salt condition at the in vitro selection stage afforded RNP receptors with higher dopamine affinity, while addition of norepinephrine in the in vitro selection milieu at the counter-selection step reinforced the selectivity of RNP receptors to dopamine against norepinephrine. Thermodynamic analyses and circular dichroismic studies of the dopamine-RNP complexes suggest that the dopamine-binding RNP with higher selectivity against norepinephrine forms a pre-organized binding pocket and that the dopamine-binding RNP with higher affinity binds dopamine through the induced-fit mechanism. These results indicate that the selection condition controls the ligand-binding mechanism of RNP receptors.

2009 Elsevier Ltd. All rights reserved.

\section{Introduction}

Fluorescent biosensors that facilitate reagentless sensitive detection of small molecules are crucial tools in the areas of therapeutics and diagnostics. ${ }^{1-3}$ The receptor-based fluorescent sensor is a representative case of fluorescent biosensors, in which the receptor component that captures the target ligand usually sets the sensitivity and selectivity of the sensor and the signal transduction component of the sensor is responsible for converting the ligand-binding event into measurable fluorescence signals. ${ }^{4-6}$ For generating the receptor component, in vitro selection, also known as SELEX (systematic evolution of ligands by exponential enrichment), ${ }^{7-9}$ offers an effective strategy for generating RNA or DNA receptors (aptamers) with appropriate affinity and specificity for various targets, for which naturally occurring protein receptors are not accessible. ${ }^{10-13}$ Modification of RNA and DNA aptamers with the fluorescence reporter component affords many RNA- and DNA-based fluorescent sensors. ${ }^{14}$ We have reported a modular strategy for tailoring fluorescent ribonucleopeptide (RNP) sensors for ATP with a variety of binding and signal-transducing characteristics. ${ }^{15-16}$

\footnotetext{
*Corresponding author. Tel: +81 77438 3585; fax: +81 774383516 e-mail address: t-morii@iae.kyoto-u.ac.jp (T.M.)
}

A RNA-derived RNP library, in which the Rev Responsive Element (RRE) RNA appended with a randomized nucleotides region was complexed with the Rev peptide, ${ }^{17-18}$ was applied for in vitro selection to obtain RNP receptors for various targets. ${ }^{19}$ RNP receptors are converted into target-specific fluorescent sensors by modification of the N-terminal of the Rev peptide with various kinds of fluorophores. ${ }^{16,20-22}$

For the fluorescent RNP sensors to realize the selective sensing of small molecules, it is necessary to obtain RNP receptors with distinct selectivity to the target ligand. The first step of the stepwise molding of fluorescent RNP sensors, namely the in vitro selection step, controls the selectivity and affinity of the sensor for the target. The way by which the substrate was immobilized to the resin is an important parameter to control the selectivity and the affinity of RNP receptors. ${ }^{23-26}$ It has also been reported that the conditions for the equilibrium binding of the library of molecules (RNA or DNA) to the target control the affinity and selectivity of aptamers. ${ }^{27}$

In this report, biologically active catecholamines are chosen as the target for the RNP receptor-based fluorescent sensor to ask a question of whether the subtle difference in the structure of small molecules could be selectively recognized by the RNP receptors and/or sensors. Catecholamines have closely related but distinct structures of the catechol ring with aliphatic chain, which is the key characteristic for each catecholamine to exert a different 
receptor activation activity. Because dopamine is a valuable heuristic bridge in defective brain chemistry study over the past medical history, ${ }^{28}$ it is of particular interest to prepare a suitable analytical tool for dopamine that will accelerate clear understanding of the relationship between the function and the structure $^{29}$ of each biologically active catecholamine. In the catecholamine biosynthesis pathway (Figure 1), dopamine is produced by the hydroxylation of L-tyrosine followed by the decarboxylation of L-dihydoxyphenylalanine (L-dopa) by aromatic L-amino acid decarboxylase. Likewise, dopamine is the intermediate precursor of norepinephrine and epinephrine. As the further response, dopamine is converted to norepinephrine by dopamine- $\beta$-hydroxylase. Finally, phenylethanolamineN-methyl transferase catalyzes conversion of norepinephrine to epinephrine. ${ }^{30}$ Each catecholamine has a distinct structure of a benzene ring with two hydroxyl groups and a terminal aminoethyl group.

In order to prepare fluorescent sensors specific for dopamine, receptors that successfully discriminate dopamine from those other catecholamine derivatives, such as norepinephrine and epinephrine, are required (Figure 1). Previously, dopaminebinding RNA aptamers were isolated by in vitro selection ${ }^{31}$ and its DNA homologues were reported to retain the dopaminebinding DNA activity. ${ }^{32}$ The RNA aptamer specifically recognized the catechol group bearing 3- and 4-hydroxyl groups, but it was relatively insensitive to the modification at the aminoethyl moiety. Thus, it is an interesting challenge to design an efficient selection scheme to isolate dopamine-binding receptors with distinct specificity over L-dopa, norepinephrine and epinephrine. We report here dopamine-binding RNP receptors obtained by various in vitro selection schemes including the counter-selection and construction of fluorescent dopamine sensors through the stepwise molding strategy. We have also investigated the mechanisms by which RNP receptors recognize dopamine and demonstrated that the condition applied for the selection step governs the recognition mechanism of RNP receptors.

(a)
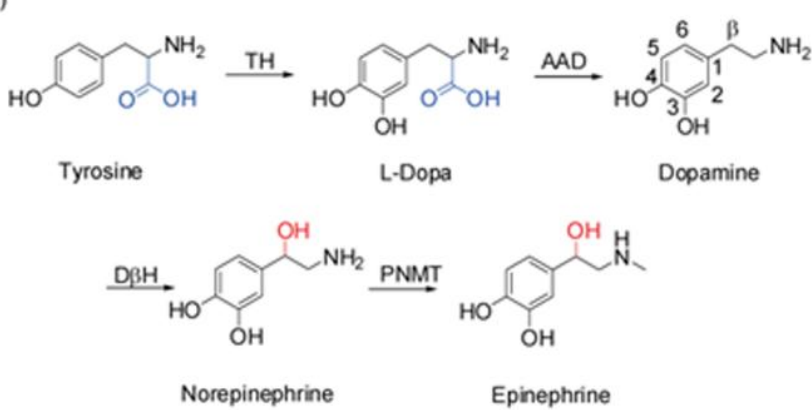

(b)

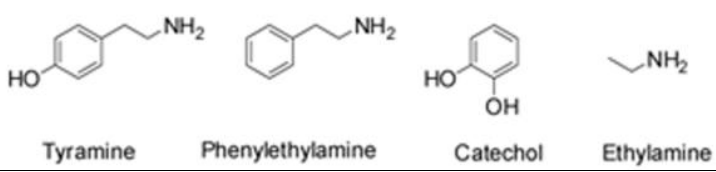

Figure 1. (a) The biosynthetic pathway for the catecholamine neurotransmitters from tyrosine. TH, tyrosine hydroxylase; AAD, aromatic Lamino acid decarboxylase; D $\beta \mathrm{H}$, dopamine- $\beta$-hydroxylase; PNMT, phenylethanolamine methyltransferase. Dopa, 3,4-dihydroxyphenylalanine. (b) Structures of ligands bearing catecholamine-related functional groups used in this study.

\section{Results}

\subsection{Design of in vitro selection schemes for obtaining dopamine-binding ribonucleopeptides.}

We have combined a negative selection step using tyrosineagarose resin at each round of the RNP selection protocol. Mannironi et al. selected dopamine-binding RNA aptamers at a quite high salt concentration (50 mM Tris- $\mathrm{HCl}, \mathrm{pH} 7.4,500 \mathrm{mM}$ $\mathrm{NaCl}$, and $5 \mathrm{mM} \mathrm{MgCl}_{2}$ ) that would avoid nonspecific charge interactions between RNA and dopamine. ${ }^{31}$ In vitro selection of RNP was carried out under two different $\mathrm{NaCl}$ concentrations 150 and $300 \mathrm{mM}$ to check the effect of salt concentrations.

RNP receptors for dopamine were selected from RNP libraries (RRENn RNP library) consisting of various lengths of randomized nucleotides, ranging from 7 to 40 nucleotides. ${ }^{22}$ The RNP library was incubated with a tyrosine-immobilized agarose resin under two different $\mathrm{NaCl}$ concentrations as the negative selection step. During this step, RNPs that showed affinity to the carboxyl group at the $\alpha$ position of the amino group would be eliminated. The flow through fraction was subjected to a second incubation with a dopamine-immobilized agarose resin at each salt condition. Unbound RNP species were extensively washed away with each binding buffer. The resin-bound RNA fractions eluted by the dopamine-containing buffer ( $5 \mathrm{mM}$ dopamine) were collected, reverse transcribed, and applied to successive RT-PCR amplification to generate a new DNA pool. DNA templates were transcribed, and the resulting RNA was complexed with the Rev peptide to prepare an RNP pool for the next round of selection.

\begin{tabular}{|c|c|c|c|c|c|c|}
\hline clone & \multicolumn{5}{|c|}{ nucleotide sequences of the randomized region } & \multirow{2}{*}{ hucleotide lengths } \\
\hline DL02 & GUA & CCUAUACUG & ACGU & cuuve & & \\
\hline DL24 & GUA & CCUAUACUG & ACGU & CUUGU & & \\
\hline DL03 & GUA & CCUAUACUG & ACGU & UCUUG & & \\
\hline DL28 & GUA & CCUAUACUG & ACGU & UCAUA & & \\
\hline DL11 & GUA & CCUAUACUG & ACGU & UCAUG & & \\
\hline DL01 & & CCUAUGCUG & cugu & CCAAUUC & & 20 nt \\
\hline DL14 & & GCCAGCCUU & ACGU & UCGCUAC & & $20 \mathrm{nt}$ \\
\hline DL31 & AUG & GCGGCGACCC & ACGU & CUCCUGt & GUU & $26 \mathrm{nt}$ \\
\hline DL26 & & GUUGUGUGCCCC & CUUGCU & GUUG & & $22 \mathrm{nt}$ \\
\hline DL19 & & UUAC & CUUUGC & GUUG & CACUUG & 19 nt \\
\hline DL29 & & AUCUGUGU & UAAGCU & GUUG & CACCGGUUGUAAGUAAAACU & $37 \mathrm{nt}$ \\
\hline DL23 & & UCCUCUAGCGA & AAGGAU & GUUG & UCGAACG & $27 \mathrm{nt}$ \\
\hline DL22 & GUA & UUUUA CUG & GCCCUC & GUUG & & 20 nt \\
\hline DL07 & UUAU & UUUUA UAA & AUGUGUA & AUUACAUC & & $26 \mathrm{nt}$ \\
\hline DL12 & $\mathrm{AGCC}$ & UUUUA AUC & CGU & & & $14 \mathrm{nt}$ \\
\hline DL27 & GCAUA & AUGACGCCUACU & & & & $17 \mathrm{nt}$ \\
\hline
\end{tabular}

Figure 2. Nucleotide sequences obtained from the randomized region of RRENn of dopamine-binding RNP receptors after 12 rounds of in vitro selection (DL-RNP pool) with a low salt concentration buffer. The numbers in parentheses indicate the number of clone with the same nucleotide sequence. Consensus sequences were shown in bold.

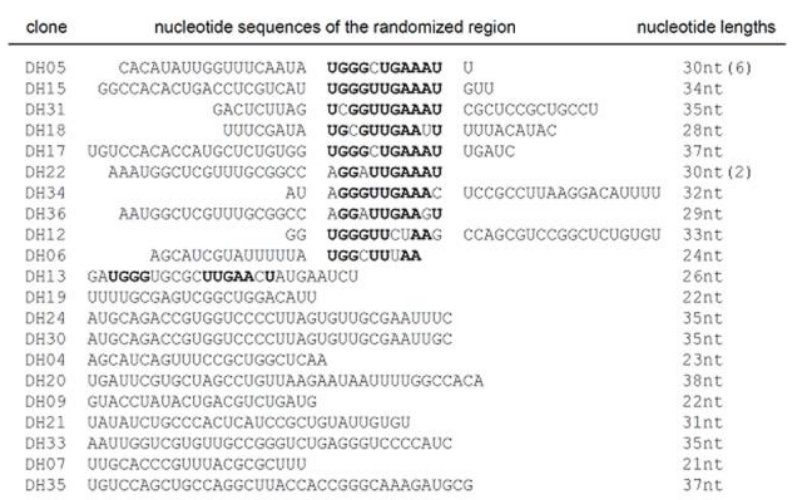

Figure 3. Nucleotide sequences obtained from the randomized region of RRENn of dopamine-binding RNP receptors after 14 rounds of in vitro selection (DH-RNP pool) with a high salt concentration buffer. The numbers in parentheses indicate the number of clone with the same nucleotide sequence. Consensus sequences were shown in bold. 
After 12 rounds of iterative selection and amplification at the $150 \mathrm{mM} \mathrm{NaCl}$ condition, 29 RNA clones were sequenced to reveal 16 unique sequences (designated as DL-RNP pool), which were composed of 14 to 37 nucleotides derived from the randomized RNA region (Figure 2). Fourteen clones (DL02) among the 29 sequenced clones were identical, and contained a highly conserved consensus sequence 5 ' CCUAUACUGACGU-3' ${ }^{\prime}$. Two other types of consensus sequences were also identified in clones that possessed 14 to 37 nucleotides in the randomized region. Similarly, after 14 rounds of the selection in the condition containing $300 \mathrm{mM} \mathrm{NaCl}$, analysis of the nucleotide sequences of 27 clones identified 21 unique sequences (designated as a DH-RNP pool), which were composed of 21 to 38 nucleotides derived from the randomized region (Figure 3). DH05 and DH22 represented six and two identical clones, respectively, shared a consensus sequence $5^{\prime}$ UGAAAU-3' . There is no homology between the nucleotide sequences deduced from the DL- and DH-RNP pools except that DH09 RNA (Figure 3) shows a partial similarity to DL02 RNA (figure 2). It turned out that each selection procedure at the different salt concentration provided unique substrate-binding RNA sequences, indicating that the specific dopamine binding by RNP is highly dependent on the salt concentration. Moreover, these consensus sequences of DL- and DH-pools showed no similarity to that of the previously reported dopamine-binding aptamers, 5'-UGUGC---GCACA-3' ${ }^{31}$

\subsection{Dopamine-binding assay of DL-and DH-RNPs based fluorescent RNP sensors.}

To investigate the affinity and the selectivity of isolated RNP receptors for dopamine, fluorescent RNP sensors were constructed according to the previously reported method. ${ }^{15,}$ 19-22, 26 The Rev peptide modified at the N-terminal with 7methoxycoumarin-3-carboxylic acid (7mC-Rev) was complexed with DL02 RNA (DL02/7mC-Rev) and DH05 RNA (DH05/7mC-Rev), the most abundant clones in the DL- and DHRNP pool, respectively. The relative ratio of fluorescence intensity $\left(I / I_{0}\right)$ in the absence $\left(I_{0}\right)$ and the presence $(I)$ of dopamine for the fluorescent RNP complex DL02/7mC-Rev at $405 \mathrm{~nm}$ increased up to 2.2-fold (Figure 4a). A nonlinear regression analysis of the titration curve yielded an equilibrium dissociation constant $\left(K_{\mathrm{D}}\right)$ of $14.9 \mu \mathrm{M}$ for the binding complex of DL02/7mC-Rev and dopamine. Similarly, DH05/7mC-Rev showed a 1.5-fold enhancement of $I / I_{0}$ in response to the increasing concentration of dopamine (Figure 4b). The standard binding isotherm obtained from the titration curve provided a $K_{\mathrm{D}}$ value of $4.1 \mu \mathrm{M}$.

The selectivity of DL02/7mC-Rev and DH05/7mC-Rev for dopamine against other catecholamine derivatives was also studied by the fluorescence titration (Figures $4 \mathrm{a}$ and $4 \mathrm{~b}$ ). The dissociation constants for the complexes of DL02/7mC-Rev and DH05/7mC-Rev with a variety of catecholamine derivatives were obtained from the fluorescence titration curves and were summarized in Table 1. The affinity of both RNPs to tyrosine and L-dopa was much lower than that to dopamine. However, both DL02/7mC-Rev and DH05/7mC-Rev failed to discriminate dopamine from norepinephrine. Deletion of the aminoethyl group (catechol) and removal of the 3-hydroxyl group of benzene ring (tyramine) or the catechol moiety (ethylamine) resulted in complete loss of binding for DL02/7mC-Rev. The observed selectivity of DL02/7mC-Rev indicates that the catechol moiety including both the 3- and 4-hydroxyl groups and the aminoethyl group of dopamine strongly contribute to the ligand binding of DL02/7mC-Rev. Judging from the low affinity of DL02/7mC-
Rev to L-dopa or tyrosine, it responded to selection pressure through tyrosine-resin elimination. Thermodynamically, the carboxyl group at the $\alpha$-position of amino group was disfavored for the complex formation with DL02/7mC-Rev. The carboxyl group prevents conjugation between ligand and DL02/7mC-Rev. In contrast, DH05/7mC-Rev showed a lower sensitivity to the 3hydroxyl group of the catechol moiety for the ligand-binding complex formation because it showed much higher affinity to tyramine as compared to DL02/7mC-Rev. DH05/7mC-Rev also showed a higher selectivity against the carboxyl group at the $\alpha$ position of amino group.

Taken together, the selection scheme including the negative selection using tyrosine-agarose resin permitted a facile preparation of dopamine-binding RNP with high selectivity for the substitution at the $\alpha$-carbon of the amino group and that at the catechol moiety. DH05 RNP obtained by the selection in the presence of $300 \mathrm{mM} \mathrm{NaCl}$ showed higher affinity to dopamine than DL02 RNP obtained with $150 \mathrm{mM} \mathrm{NaCl}$. DH05/7mC-Rev exhibited selectivity and affinity that are comparable to the previously reported RNA aptamers. ${ }^{31}$ However, the selectivity of these RNP for the substitution at the $\beta$-carbon of the aliphatic chain remains to be improved.

(a)

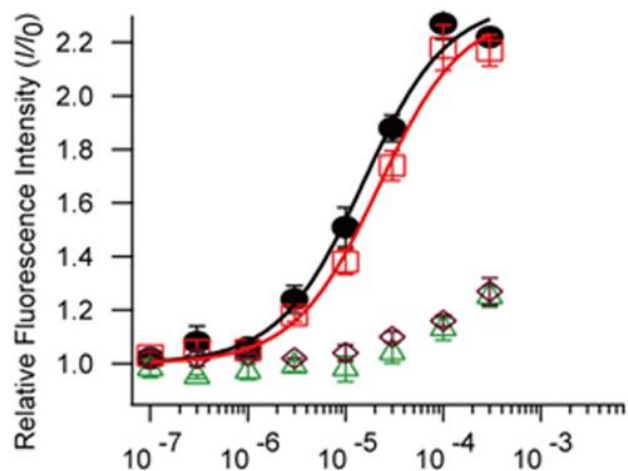

(b)

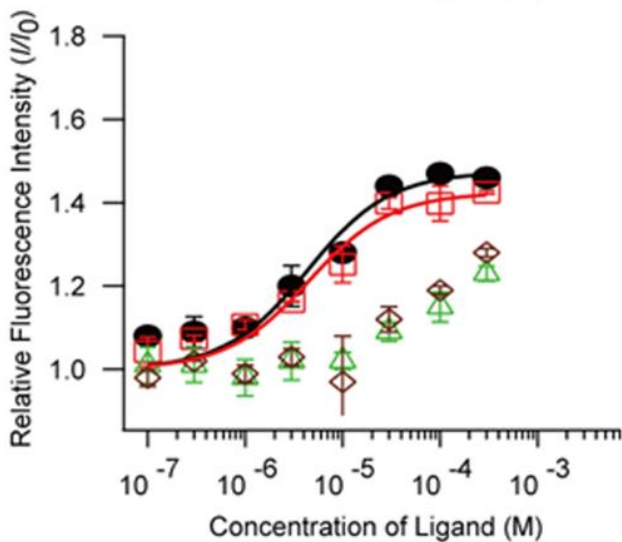

Figure 4. Titration curves for the changes of relative fluorescence intensity $\left(I / I_{0}\right)$ for (a) DL02/7mC-Rev and (b) DH05/7mC-Rev with dopamine (filled black circles), norepinephrine (open red squares), L-tyrosine (open green triangles), or L-dopa (open blown diamonds).

\subsection{Modification of the in vitro selection scheme by including a counter-selection step.}

We next applied a new selection scheme to isolate RNP that would discriminate dopamine against norepinephrine. The $\mathrm{DH}$ RNP pool obtained after 15 rounds of in vitro selection in the presence of $300 \mathrm{mM} \mathrm{NaCl}$ was subsequently subjected to a counter-selection $^{33-34}$ by using norepinephrine as a competitive ligand, which differed from dopamine in a single hydroxyl group at the $\beta$-position of aliphatic chain (Figure 1a). In the counter 
Table 1. Equilibrium dissociation constants $K_{\mathrm{D}}(\mu \mathrm{M})$ of dopamine-binding RNP for complexes with catecholamine derivatives.

\begin{tabular}{|c|c|c|c|c|c|}
\hline ligand & DL02 & DH05 & DHc25 & DHc58 & DHc65 \\
\hline dopamine & $14.9 \pm 2.3$ & $4.1 \pm 1.4$ & $60 \pm 9.5$ & $42 \pm 6$ & $3.2 \pm 0.4$ \\
\hline L-tyrosine & $>300$ & $247 \pm 33$ & $>300$ & $>300$ & $>300$ \\
\hline L-dopa & $86.4 \pm 3.0$ & $161 \pm 31$ & $>300$ & $>300$ & $>300$ \\
\hline norepinephrine & $21.7 \pm 3.5$ & $6.2 \pm 1.5$ & $326 \pm 28$ & $92.4 \pm 14$ & $4.2 \pm 0.4$ \\
\hline epinephrine & $26.4 \pm 4.0$ & $14.2 \pm 2.6$ & $173 \pm 28$ & $99 \pm 20$ & $20.0 \pm 6.0$ \\
\hline catechol & $>300$ & $>300$ & $>300$ & $235 \pm 62$ & $108 \pm 13.2$ \\
\hline tyramine & $>300$ & $27 \pm 5.5$ & $>300$ & $>280$ & $145 \pm 19.7$ \\
\hline ethylamine & $>300$ & $>300$ & $>300$ & $>300$ & $>300$ \\
\hline phenethylamine & $>300$ & $>300$ & $>300$ & $>300$ & $>300$ \\
\hline
\end{tabular}

selection step, RNPs were washed off the column with a binding buffer containing norepinephrine $(1 \mathrm{mM})$. The resin-bound RNPs were then specifically eluted by using a buffer containing $5 \mathrm{mM}$ dopamine. After additional 8 cycles of selection including the counter selection step, more convergent sequences were obtained as shown in Figure 5, designated as a DHc-RNP pool. It is noteworthy to mention that the isolated 14 clones were unique to the DHc-RNP pool and the consensus sequences 5'AGCAU---GCU--UA-3' found in the DHc-RNP pool was completely different from that of the starting DH-RNP pool.

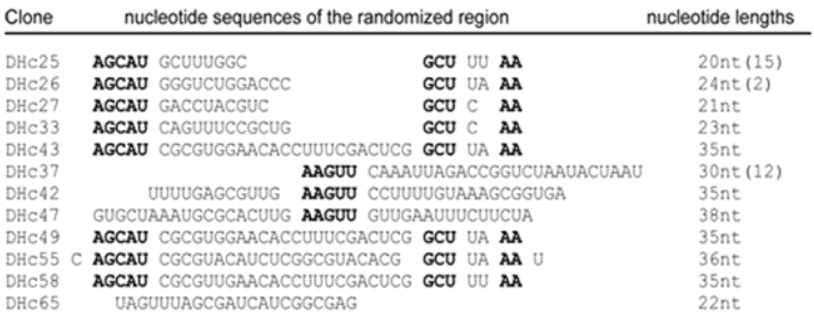

Figure 5. Nucleotide sequences obtained from the randomized region of RRENn of dopamine-binding RNP receptors isolated from the additional 8 rounds of counter selection using norepinephrine for DH RNA pool. The numbers in parentheses indicate the number of clone with the same nucleotide sequence. Consensus sequences were shown in bold.

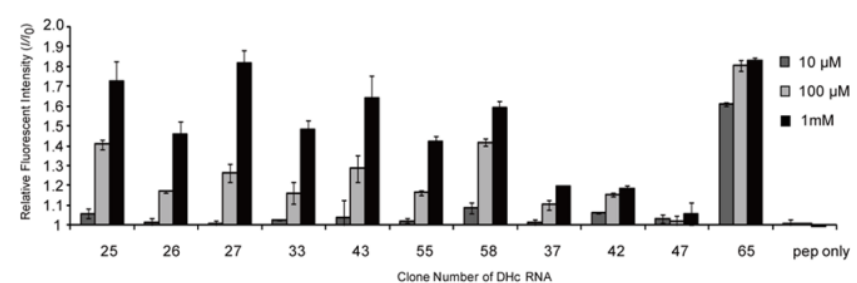

Figure 6. Changes in the relative fluorescent intensity $\left(I / I_{0}\right)$ for the complexes of DHc RNAs and 7mC-Rev in the absence or presence of various concentrations $(10 \mu \mathrm{M}, 100 \mu \mathrm{M}, 1 \mathrm{mM})$ of dopamine were evaluated at $390 \mathrm{~nm}$.

Each RNP from the DHc-RNP pool was subjected to a simple screening for its dopamine-binding by measuring $I / I_{0}$ of fluorescent DHc-RNPs, which were formed by the complex formation of RNA in the DHc pool with $7 \mathrm{mC}-\mathrm{Rev}$, in the absence or presence of various concentrations of dopamine (10 $\mu \mathrm{M}, 100 \mu \mathrm{M}, 1 \mathrm{mM}$ ) and were summarized in Figure 6. This simple functional evaluation indicated that changes in the fluorescence signal are significant for the $7 \mathrm{mC}-\mathrm{Rev}$ complexes of DHc25, DHc27, DHc43, DHc58 and DHc65. Comparison of $I / I_{0}$ values at three different dopamine concentrations $(10 \mu \mathrm{M}$,
$100 \mu \mathrm{M}, 1 \mathrm{mM}$ ) suggests that DHc25, DHc42, DHc58 and DHc65 show high affinity to dopamine. Among the fluorescent DHc-RNPs, the dominant clone DHc25/7mC-Rev and minor clones DHc58/7mC-Rev and DHc65/7mC-Rev were selected for further analyses of their recognition mode of catecholamines.

Titration of changes of the fluorescence intensities for DHc $25 / 7 \mathrm{mC}-$ Rev with dopamine gave a $K_{\mathrm{D}}$ of $60 \mu \mathrm{M}$ for the complex. The $K_{\mathrm{D}}$ value for the binding complex of norepinephrine was $326 \mu \mathrm{M}$. Comparison of the binding affinity of DHc25/7mC-Rev to other catecholamine derivatives (Table 1) revealed that DHc $25 / 7 \mathrm{mC}-\mathrm{Rev}$, the dominant RNP in the DHc pool, had a high selectivity to the aminoethyl chain of dopamine, norepinephrine and epinephrine, and showed no detectable binding affinity to catechol, tyramine, ethylamine or phenylethylamine. Tyrosine and L-dopa were not effective substrates for DHc25/7mC-Rev. DHc58/7mC-Rev also showed selective binding to dopamine, but not as specific as DHc $25 / 7 \mathrm{mC}$-Rev. The dopamine complex of DHc58/7mC-Rev was formed with $K_{\mathrm{D}}$ of $42 \mu \mathrm{M}$, while its complexes of norepinephrine and epinephrine were formed with $K_{\mathrm{D}}$ of $92 \mu \mathrm{M}$ and $99 \mu \mathrm{M}$, respectively. Both DHc25/7mC-Rev and DHc58/7mC-Rev show binding characteristics that are different from DL02/7mC-Rev and DH05/7mC-Rev obtained from the early generation of the in vitro selection. On the other hand, the minor DHc65/7mC-Rev bounds catecholamines in the similar manner as DH05/7mC-Rev obtained from the parent DH-RNP pool. DHc65/7mC-Rev formed stable binding complexes of dopamine and norepinephrine with $K_{\mathrm{D}}$ values of 3.2 and $4.2 \mu \mathrm{M}$, respectively. Both DHc25/7mC-Rev and DHc58/7mC-Rev exhibited improved binding selectivity for dopamine with the loss of binding affinity. The competitive binding condition reduced the population of RNP species that accommodate the hydroxyl group at the $\beta$-position of the aliphatic chain of norepinephrine. 
(a)

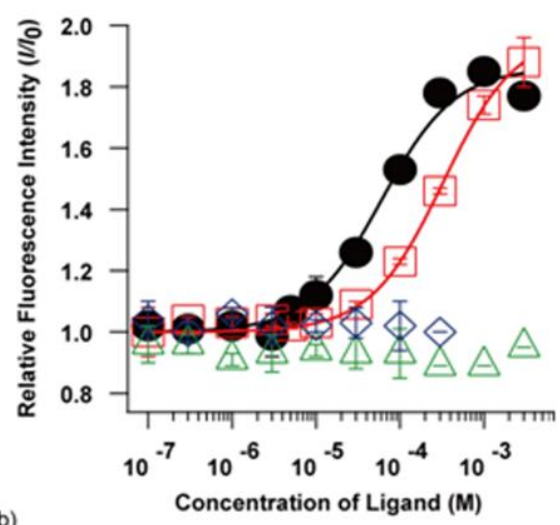

(b)

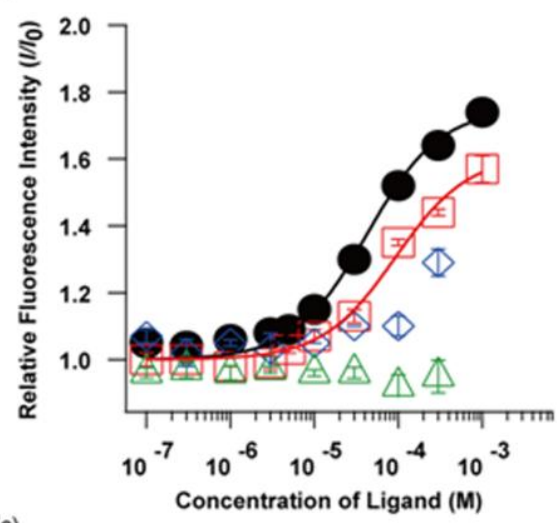

(c)

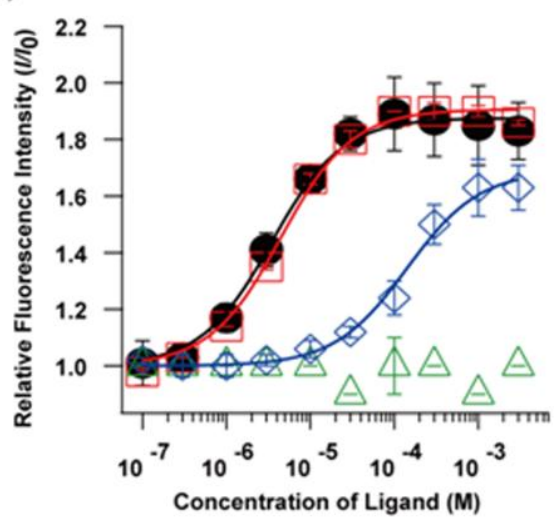

Figure 7. Saturation curves for the fluorescence emission intensity of (a) DHc25/7mC-Rev, (b) DHc58/7mC-Rev and (c) DHc65/7mC-Rev by titration with dopamine (filled black circles), norepinephrine (open red squares), L-tyrosine (open green triangles), or epinephrine (open blue diamonds).

\subsection{Determination of thermodynamic parameters for the binding complexes of DHc RNPs and catecholamines.}

Possible secondary structures of the RNA subunits of selected RNP were obtained by using mfold v3.0 algorithm, ${ }^{35-37}$ and shown in Figure S1. The overall secondary structures were calculated to maintain the secondary structure of the RRE sequence reported previously ${ }^{17}$. Both DHc25 and DHc58 RNPs are expected to form AU bulge and UUAA loop structures (Figures S1a and S1b). These structures would provide similar binding characteristics DHc25 and DHc58 RNPs on the catecholamine recognition. The secondary structure of DHc65 RNP, the minor RNP in the DHc-RNP pool, is different from that of DHc25 or DHc58 RNP. In addition, the secondary structures suggested for DHc25, DHc58 and DHc65 RNP are quite different from the proposed secondary structures for the dopamine-binding RNA aptamers ${ }^{31}$
We next investigated thermodynamic parameters for the binding complexes of dopamine, norepinephrine and epinephrine with DHc25/7mC-Rev, DHc58/7mC-Rev and DHc65/7mC-Rev. The $K_{\mathrm{D}}$ values of these complexes were obtained at $4,10,15,20$ and $25^{\circ} \mathrm{C}$, and were shown as the van't Hoff plot (Figure S3). ${ }^{38-40}$ The data are fitted to the first order function of van't Hoff equation. ${ }^{41}$ Thermodynamic parameters obtained from the van't Hoff analysis of the binding constants for DHc25/7mC-Rev, DHc58/7mC-Rev and DHc65/7mC-Rev are summarized in Table 2.

DHc25/7mC-Rev formed a dopamine-binding complex with enthalpy changes $(\Delta \mathrm{H})$ of $-17.5 \mathrm{kcal} \mathrm{mol}^{-1}$ and unfavorable entropy changes $(-\mathrm{T} \Delta \mathrm{S})$ of $12.2 \mathrm{kcal} \mathrm{mol}^{-1}$ at $4{ }^{\circ} \mathrm{C}$. Binding of norepinephrine to $\mathrm{DHc} 25 / 7 \mathrm{mC}-\mathrm{Rev}$ was due to $\Delta \mathrm{H}$ of $-13.5 \mathrm{kcal}$ $\mathrm{mol}^{-1}$ and $-\mathrm{T} \Delta \mathrm{S}$ of $9.0 \mathrm{kcal} \mathrm{mol}{ }^{-1}$. Formation of a binding complex of DHc $25 / 7 \mathrm{mC}-\mathrm{Rev}$ and epinephrine associated with $\Delta \mathrm{H}$ of $-14.8 \mathrm{kcal} \mathrm{mol}^{-1}$ and $-\mathrm{T} \Delta \mathrm{S}$ of $10.0 \mathrm{kcal} \mathrm{mol}^{-1}$ (Table 2). Formation of the binding complex of DH25/7mC-Rev and catecholamine reveals that the favorable enthalpy changes for the binding of catecholamine are always offset by large unfavorable entropy changes. DHc58/7mC-Rev formed more energetically stable complexes with dopamine as compared to DHc $25 / 7 \mathrm{mC}-$ Rev. Though the enthalpy changes for the dopamine complex formation of DHc58/7mC-Rev is larger than DHc25/7mC-Rev, it associates with larger unfavorable entropy changes (Table 2). Binding of catecholamines exhibited the enthalpy-entropy compensation phenomena for both DHc $25 / 7 \mathrm{mC}-$ Rev and DHc58/7mC-Rev. ${ }^{42}$ Interactions between the 4-hydroxyl group substituted aromatic ring of catecholamine with DHc25/7mC-Rev and DHc58/7mC-Rev are more critical than that between the aliphatic chain of dopamine, norepinephrine or epinephrine. Presence of the hydroxyl group at the aliphatic chain of norepinephrine reduced the enthalpy changes for the complex formation with DHc25/7mC-Rev and DHc58/7mC-Rev. The methyl group at the terminal amino group of epinephrine contributed to further reduction of the binding affinity of epinephrine. Because DHc25/7mC-Rev and DHc $58 / 7 \mathrm{mC}-$ Rev reveal quite similar contributions of both enthalpy and entropy changes for the dopamine-binding complex formation, the AU bulge and the UUAA loop (Figures $\mathrm{S} 1 \mathrm{a}$ and $\mathrm{S} 1 \mathrm{~b}$ ) that are common for both RNP would form the binding-pocket of these RNPs. The dopamine-binding complex of DHc58/7mC-Rev exhibited a slightly higher stability than that of DHc25/7mC-Rev, which likely results from a stabilization of the putative binding site by the longer stem region adjacent to the loop. However, DHc25/7mC-Rev, the dominant RNP in the DHc-RNP pool, showed higher selectivity over norepinephrine than DHc58/7mC-Rev.

The minor RNP in the DHc-RNP pool, DHc65/7mC-Rev, showed a high affinity to dopamine but almost no specificity to norepinephrine and epinephrine. Isolation of DHc65 RNP witnesses a process of functional convergence of RNP during the selection scheme in the presence of the competitor, though the RNA sequence of DHc65 RNP does not share the consensus sequence found in the DH-RNP pool. DHc65 RNP displayed significantly different binding characteristics as compared to the other RNP from the DHc-pool, such as DHc25 and DHc58 RNP. Complex formation of DHc65/7mC-Rev with dopamine, norepinephrine or epinephrine revealed quite similar thermodynamic parameters. Both the enthalpy and entropy changes for the dopamine binding of DHc65 RNP are much larger than that of DHc25 or DHc58 RNP at $4{ }^{\circ} \mathrm{C}$, (Table 1). Though DHc65/7mC-Rev showed similar binding affinities to dopamine, norepinephrine and epinephrine, it prominently recognized both the 3- and 4-hydroxyl groups of catechol (Table 
Table 2 Thermodynamic parameters of dopamine, norepinephrine and epinephrine binding to DHc25 RNP, DHc58 RNP, and DHc65 RNP at $4{ }^{\circ} \mathrm{C}$.

\begin{tabular}{|c|c|c|c|c|}
\hline DHcRNA/7mC- Rev & Catecholamine & $\Delta \mathrm{H}\left(\mathrm{kcal} \mathrm{mol}^{-1}\right)$ & $-\mathrm{T} \Delta \mathrm{S}\left(\mathrm{kcal} \mathrm{mol}^{-1}\right)$ & $\Delta G_{4}{ }^{\circ} \mathrm{C}\left(\mathrm{kcal} \mathrm{mol}^{-1}\right)$ \\
\hline \multirow[t]{3}{*}{ DHc25/7mC } & Dopamine & $-17.5 \pm 0.5$ & $12.2 \pm 0.4$ & $-5.30 \pm 0.1$ \\
\hline & Norepinephrine & $-13.5 \pm 0.4$ & $9.0 \pm 0.4$ & $-4.49 \pm 0.0$ \\
\hline & Epinephrine & $-14.8 \pm 0.1$ & $10.0 \pm 0.1$ & $-4.81 \pm 0.0$ \\
\hline \multirow[t]{3}{*}{$\mathrm{DHc} 58 / 7 \mathrm{mC}$} & Dopamine & $-20.5 \pm 0.0$ & $14.7 \pm 0.1$ & $-5.75 \pm 0.0$ \\
\hline & Norepinephrine & $-16.9 \pm 0.2$ & $11.8 \pm 0.2$ & $-5.05 \pm 0.0$ \\
\hline & Epinephrine & $-14.8 \pm 0.0$ & $9.6 \pm 0.0$ & $-5.22 \pm 0.0$ \\
\hline \multirow[t]{3}{*}{$\mathrm{DHc} 65 / 7 \mathrm{mC}$} & Dopamine & $-24.9 \pm 0.2$ & $17.9 \pm 0.3$ & $-7.03 \pm 0.1$ \\
\hline & Norepinephrine & $-24.8 \pm 0.1$ & $17.9 \pm 0.1$ & $-6.91 \pm 0.1$ \\
\hline & Epinephrine & $-23.5 \pm 0.2$ & $17.0 \pm 0.2$ & $-6.51 \pm 0.1$ \\
\hline
\end{tabular}

1). The observed large negative entropy changes associated with the formation of dopamine, norepinephrine and epinephrine complexes are quite similar each other, indicating that tertiary structural rearrangements for the formation of the complexes of DHc65/7mC-Rev with dopamine, norepinephrine and epinephrine take place in the similar degree. Although the number of nucleotides utilized for the ligand binding is similar for DHc65 RNP (22 nt) and DHc25 RNP (20 nt), DHc65 RNP forms the most stable dopamine-RNP complex studied here. The fact that DHc65 RNP shows a different recognition pattern from that of DHc25 RNP likely correlates to the difference in the secondary structures for these RNPs (Figure S1).

\subsection{Circular dichroismic measurements of the dopamine- binding RNPs.}

Solution structures of DHc RNP in absence or presence of dopamine were studied by circular dichroism (CD) measurements ${ }^{43}$ to understand a possible correlation between the structures of RNP and their ligand-binding complexes. The CD spectra of DHc25 RNA, DHc25/7mC-Rev, and a complex of DHc25/7mC-Rev and dopamine are shown in Figure 8a. The DHc25 RNA had a strong positive band near $265 \mathrm{~nm}$ and a negative peak near $240 \mathrm{~nm},{ }^{44}$ the characteristic feature of A-form RNA. The CD spectra of DHc $25 / 7 \mathrm{mC}-\mathrm{Rev}$ brought slight reduction in the molar ellipticity at $265 \mathrm{~nm}$ and a larger negative band at $220 \mathrm{~nm}$, which was induced by the conformational transition of the $7 \mathrm{mC}$-Rev peptide from a random to an $\alpha$-helical structure upon binding to the RRE sequence. The CD spectrum of DHc25/7mC-Rev in the presence of $1 \mathrm{mM}$ dopamine was almost identical to that of DHc25/7mc-Rev. Binding of dopamine to DHc $25 / 7 \mathrm{mC}-\mathrm{Rev}$ caused little or no change in the molar ellipticity at $265 \mathrm{~nm}$. These results indicated that dopamine binds to a rather pre-organized binding site in DHc25 RNP. DHc58 RNP revealed almost no conformational change upon the dopamine binding. Although DHc25 RNP discriminate dopamine against norepinephrine, both the dopamine and norepinephrine complexes of DHc25 RNP revealed quite similar CD spectra (Figures S3 and S4). This was also the case for DHc58 RNP.

In contrast, DHc65 RNP revealed a large conformational change upon its dopamine-binding complex formation (Figure 8c). DHc65 RNA is also in the A-form structure and the formation of DHc65/7mC-Rev also induced the negative CD bands around $220 \mathrm{~nm}$, assignable for the $\alpha$-helix formation. Upon formation of a complex of DHc65/7mC-Rev and dopamine, a negative band was appeared at $290 \mathrm{~nm}$ and the positive band at $260 \mathrm{~nm}$ was increased. The result indicates that DHc65 RNP binds to dopamine by the induced-fit mechanism.

\section{Discussion}

The in vitro selection scheme including the negative selection step with tyrosine successfully reduced the population of RNP that showed affinity to tyrosine and L-dopa, the catecholamine derivatives with the carboxyl group. The high salt conditions applied in the selection step would reduce the interaction between the positively charged terminal amino group of dopamine and the negatively charged phosphate groups of RNP. In such conditions, it is expected that the complex formation of dopamine and RNP is dominantly governed by the interaction of the catechol group and the aliphatic side chain with RNP. This was born out in the present selection scheme. The in vitro selection with dopamine-bound resin at the high salt condition afforded DH05/7mC-Rev that formed a more stable dopaminebinding complex than DL02/7mC-Rev, which was obtained by in vitro selection in the low salt condition. The fluorescent RNP sensor with the high affinity to dopamine DH05/7mC-Rev showed lower selectivity to tyramine than DL02/7mC-Rev obtained from in vitro selection at the low salt condition. Thus, application of the high salt selection scheme that is expected to reduce the nonspecific ligand binding governed by the charge interaction does not always afford RNP with a higher ligand selectivity. On the other hand, the in vitro selection scheme including the counter selection step from the DHc RNP pool, where norepinephrine was utilized as the competitive ligand, resulted in isolation of RNPs that showed selectivity to dopamine over norepinephrine. The dominant RNP in the DHcRNP pool, DHc25/7mC-Rev, showed lower binding affinity but the higher selectivity to dopamine than DH05/7mC-Rev obtained from the parent DH-RNP pool. The obtained thermodynamic data revealed that our selection scheme against the undesired ligand attributed discrimination in the interaction of RNP with dopamine, norepinephrine and epinephrine, while the selection scheme to enhance the selectivity of RNP did not automatically produce RNP with high affinity in the present study. 
(a)

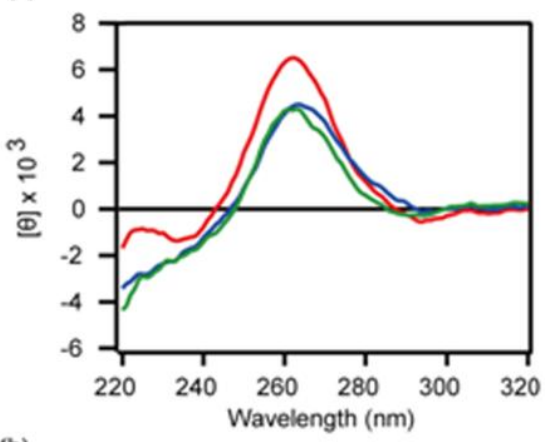

(b)

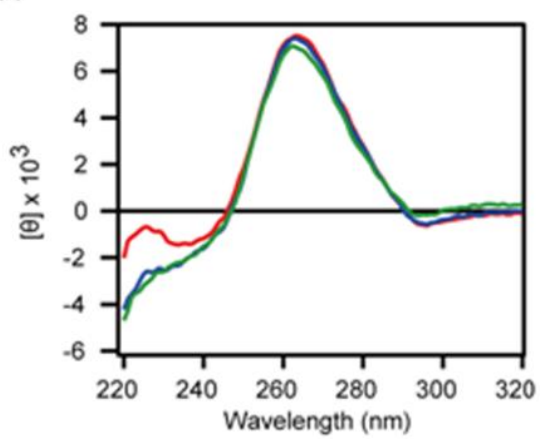

(c)

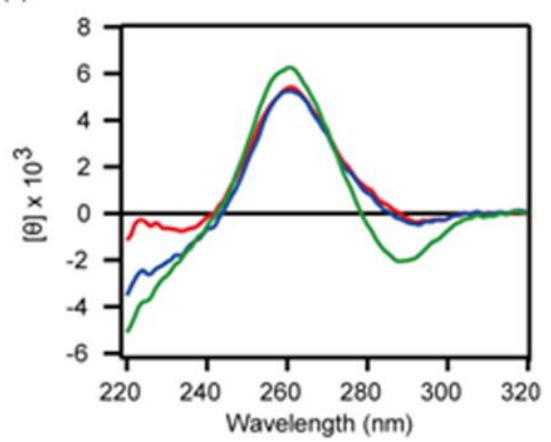

Figure 8. The CD spectra of (a) DHc25, (b) DHc58 and (c) DHc65. RNA only (red line), RNP only (blue line), and RNP with dopamine (green line) spectra were shown, respectively.

CD spectral and thermodynamic data for the ligand-binding complexes of DHc25/7mC-Rev and DHc58/7mC-Rev are consistent with the pre-organized type of ligand-binding mechanism. The thermodynamic data indicates that the catechol ring is the critical recognition site for almost all the RNP selected and that the steric interference at the aliphatic chain is prone to lower the ligand-binding affinity for DHc25/7mC-Rev. DHc65/7mC-Rev forms catecholamine-binding complexes through the induced-fit mechanism, in which the equilibrium for the complex formation is often governed by faster $k_{\text {on }}$ and $k_{\text {off }}$ than the ligand-binding equilibrium of the pre-organized binding pocket. ${ }^{45-46}$ In order for the selection pressure to reach the affinity maturation, RNPs with the pre-organized binding pocket have to be washed off from the bound-resin with a large excess buffer or a longer incubation time to obtain RNPs that form ligand-binding complexes governed by slower kinetics. ${ }^{47-49} \mathrm{~A}$ selection pressure to emphasize the difference in kinetic behaviors of RNPs in the pool would be an alternative approach to obtain RNP with the high affinity and selectivity.

\section{Conclusions}

By applying the conditional selection scheme, we have obtained dopamine-binding RNPs with various binding characteristics and developed fluorescent RNP sensors for dopamine that show moderate selectivity against norepinephrine, and high selectivity over other catechol amines, such as epinephrine, L-dopa and tyrosine. The ligand-binding pockets are pre-organized for DHc25 and DHc58 RNP that showed similar recognition mode and binding mechanisms to dopamine. DHc25 and DHc58 RNP show higher selectivity against norepinephrine and epinephrine than DHc65 RNP, which forms a dopamine complex by the induced-fit mechanism. A selection scheme including a counter selection step by using a competitor norepinephrine afforded dopamine-binding RNPs with expected specificity. Based on the investigation of the thermodynamic parameters of the catecholamine-RNP complexes, the binding processes of catecholamines to RNP are all driven by enthalpy changes and exhibit the enthalpy-entropy compensation phenomena. Further refinements of the selection scheme, such as the kinetic control for the selection step, would realize in vitro selection of RNP with enhanced affinity and selectivity.

\section{Materials and Methods}

Dopamine immobilized agarose resin was purchased from ICN. L-Tyrosine immobilized on cross-linked $4 \%$ beaded agarose, L-dopa, norepinephrine, epinephrine, phenytylamine and tyrosine were purchased from Sigma-Aldrich. Catechol was purchased from Wako Chemicals. Tyramine was purchased from Tokyokasei. Klenow DNA polymerase, restriction enzyme (BamHI and EcoRI) and T4 polynucleotide kinase were purchased from New England Biolab. Gel electrophoresis grade acrylamide and bisacrylamide were obtained from Wako Chemicals. Rev peptide modified with acetic acid (Ac-Rev) and 7-methoxycoumarin-3-carboxylic acid (7mC-Rev) were synthesized as described previously. ${ }^{15,19}$

\subsection{Nucleic Acid Preparations.}

The nucleic acids used in this study were prepared according to the procedure previously reported. ${ }^{22,}{ }^{26}$ Concentrations of RNA were determined by UV spectroscopy.

\subsection{In vitro selection of dopamine-binding $R N P$.}

The RRENn RNA library was prepared as previously reported ${ }^{19}$ in the low salt buffer $(100 \mu \mathrm{L})[50 \mathrm{mM}$ Tris- $\mathrm{HCl}(\mathrm{pH}$ 7.6), $150 \mathrm{mM} \mathrm{NaCl}, 0.005 \%$ Tween $20,0.02 \%$ ascorbic acid] or in the high salt buffer $(100 \mu \mathrm{L})[50 \mathrm{mM}$ Tris-HCl $(\mathrm{pH} 7.6)$, $300 \mathrm{mM} \mathrm{NaCl}, 0.005 \%$ Tween $20,0.02 \%$ ascorbic acid] by using $2 \mu \mathrm{M}$ RNA and $3 \mu \mathrm{M}$ Ac-Rev. Firstly, the negative selection step was carried out by using tyrosine-agarose resin (2 $\mathrm{mM}$ ). RNP was incubated with the tyrosine-immobilized agarose resin for $30 \mathrm{~min}$ on ice. The RNP-bound tyrosineagarose resin was washed three times with $300 \mu$ of the low salt buffer. The flow-through fraction was subjected to the incubation with the dopamine- agarose resin $(6 \mu \mathrm{M})$ in the low salt buffer. The RNP-bound resin was washed three times with $300 \mu \mathrm{l}$ of the low salt buffer. RNP bound to the resin was eluted with the low salt buffer containing $5 \mathrm{mM}$ dopamine $(150 \mu \mathrm{L})$ for two times. RNA of the recovered RNP was precipitated with ethanol and resuspended in TE buffer $(50 \mu \mathrm{L})$. After reverse transcription with AMV(Avian Myeloblastosis Virus) reverse transcriptase (Promega) of the selected RNA using the 3'-DNA primer used in PCR amplification and successive PCR amplification (RT-PCR) using the 5' - and 3'-DNA primer, DNA templates were transcribed and the resulting RNAs were subjected to the next round of selection. After 12 rounds of low salt buffer selection, collected RNP pool was designated as the DL-RNP pool. In vitro selection in the high salt buffer was 
carried out in the similar manner for 14 rounds of selection to give the DH-RNP pool.

\subsection{Counter selection of dopamine binding ribonucleopeptide with presence of norepinephrine (RNA/Rev).}

The DH-RNP pool obtained from the high salt condition was subjected to another 8 rounds of selection by using an equilibrium binding buffer $(100 \mu \mathrm{L})$ containing $50 \mathrm{mM}$ Tris- $\mathrm{HCl}$ (pH 7.6), $300 \mathrm{mM} \mathrm{NaCl}, 0.005 \%$ Tween $20,0.02 \%$ ascorbic acid, $1 \mathrm{mM}$ norepinephrine and the RRENn RNP library $(2 \mu \mathrm{M}$ RNA and $3 \mu \mathrm{M}$ Ac-Rev). RNP and the dopamine-immobilized agarose resin $(6 \mu \mathrm{M})$ were incubated on ice for $30 \mathrm{~min}$. The resin was washed three times with a buffer $(300 \mu \mathrm{L})$ containing $50 \mathrm{mM}$ Tris- $\mathrm{HCl}$ (pH 7.6), $300 \mathrm{mM} \mathrm{NaCl}$ and $5 \mathrm{mM} \mathrm{MgCl}_{2}$. The resin-bound RNPs were eluted twice by the high salt buffer containing $5 \mathrm{mM}$ dopamine. RNA of the recovered RNP was precipitated with ethanol and resuspended in TE buffer $(50 \mu \mathrm{L})$. After reverse transcription with AMV reverse transcriptase (Promega) of the selected RNA using the 3'-DNA primer used in PCR amplification and successive PCR amplification (RTPCR) using the 5'- and 3'-DNA primer, DNA templates were transcribed and the resulting RNAs were subjected to the next round of selection.

\subsection{Sequencing Analysis of Selected RNA}

Selected RNA pools were converted to DNA and PCRamplified to introduce BamHI and EcoRI restriction sites by using primers 5'-GCGGGATCCTTTCGGCCTGTACCGTCA3' and 5' CGGAATTCTAATACGACTCACTATAGG-3'. After enzymatic digestions, DNAs were cloned into the pUC 19 vector using Ligation Kit ver 2 (TaKaRa) and sequenced using a BigDye Terminator Cycle Sequencing Kit (Applied Biosystems) with a model 377 DNA sequencer (Applied Biosystems)

\subsection{Fluorescence measurements on the microplate.}

The 96-well fluorescence measurements were performed on a Wallac ARVOsx 1420 multilabel counter. The binding assay was evaluated by using the following conditions: $1 \mu \mathrm{M}$ RNA and $1 \mu \mathrm{M} 7 \mathrm{mC}-\mathrm{Rev}$ in $50 \mathrm{mM}$ Tris- $\mathrm{HCl}$ (pH 7.6), $5 \mathrm{mM} \mathrm{MgCl}_{2}$, $0.005 \%$ Tween 20 and $0.02 \%$ ascorbic acid with $150 \mathrm{mM} \mathrm{NaCl}$ (DL-RNP) or with $300 \mathrm{mM} \mathrm{NaCl}$ (DH or DHc-RNP). Wellmixed samples with different concentration of the ligands bearing catecholamine-related functional groups were incubated at $4{ }^{\circ} \mathrm{C}$ for 20 minutes, then emission spectra were measured $\left(\lambda_{\mathrm{ex}}=355 \mathrm{~nm}, \lambda_{\mathrm{em}}=390 \mathrm{~nm}\right)$.

$F_{\text {obs }}=\mathrm{A}\left(\left([\mathrm{RNP}]_{\mathrm{T}}+\left[\right.\right.\right.$ substrate $\left._{\mathrm{T}}+K_{\mathrm{D}}\right)-\left(\left([\mathrm{RNP}]_{\mathrm{T}}+\left[\text { substrate }_{\mathrm{T}}+K_{\mathrm{D}}\right)^{2}-\right.\right.$ $\left.\left.4[\mathrm{RNP}]_{\mathrm{T}}[\text { substrate }]_{\mathrm{T}}\right)^{1 / 2}\right) / 2[\mathrm{RNP}]_{\mathrm{T}}$

where $\mathrm{A}$ is the increase in fluorescence at saturating substrate concentrations $\left(\mathrm{F}_{\max }-\mathrm{F}_{\min }\right), K_{\mathrm{D}}$ is the equilibrium dissociation constant, and $[\mathrm{RNP}]_{\mathrm{T}}$ and $[\text { substrate }]_{\mathrm{T}}$ are the total concentrations of RNP and the substrate, respectively.

\subsection{RNA secondary structure prediction.}

Prediction of the secondary structure of DHc25 RNA, DHc 58 RNA and DHc 65 RNA by using Mfold v3.0 algorithm (offered at http://frontend.bioinfo.rpi.edu/applications/mfold/cgibin/rna-form1.cgi.). Folding was done at $37^{\circ} \mathrm{C}$ with $1 \mathrm{M} \mathrm{NaCl}$, specifying that the RRE region is in the reported secondary structure. ${ }^{35-37}$

\subsection{Thermodynamic parameter of the RNP-ligand binding complexes.}

RNP $(0.5 \mu \mathrm{M}$ RNA: $0.5 \mu \mathrm{M} 7 \mathrm{mC}-\mathrm{Rev})$ samples in binding buffer $50 \mathrm{mM}$ Tris- $\mathrm{HCl}$ (pH 7.6), $300 \mathrm{mM} \mathrm{NaCl}, 5 \mathrm{mM} \mathrm{MgCl}$, $0.005 \%$ Tween $20,0.02 \%$ ascorbic acid with different concentration of catecholamine were prepared. Samples after well-mixed were incubated at different temperature: 4, 10, 15, 20 and $25{ }^{\circ} \mathrm{C}$ for 20 minutes. Fluorescent intensity of samples was measured $\left(\lambda_{\mathrm{ex}}=355 \mathrm{~nm}, \lambda_{\mathrm{em}}=390 \mathrm{~nm}\right)$ by using Hitachi F7000 fluorescent spectrophotometer.

Through plot of $\ln 1 / K_{\mathrm{D}}$ against $1 /$ Temperature (Kelvin), both $\Delta \mathrm{H}^{\theta}$ and $\Delta \mathrm{S}^{\theta}$ were extracted. Consequently, the changes in Gibbs free energy were calculated by the following formula ${ }^{50}(\mathrm{~T}=298$ $\mathrm{K}$ and $\mathrm{R}=8.314 \mathrm{~J} \mathrm{~K}^{-1} \mathrm{~mol}^{-1}$ ).

$$
\begin{aligned}
& \text { In } 1 / K_{\mathrm{D}}=-\Delta \mathrm{H}^{\theta} / \mathrm{RT}+\Delta \mathrm{S}^{\theta} / \mathrm{R} \\
& -\mathrm{T} \Delta \mathrm{S}^{\theta}=\Delta \mathrm{G}^{\theta}-\Delta \mathrm{H}^{\theta}
\end{aligned}
$$

\subsection{Circular Dichroism Spectroscopy Measurements.}

Circular dichroism spectra were recorded on a Jasco J-725J spectropolarimeter (Jasco, Inc., Easton, MD) interfaced with a computer and equipped with a heating/cooling device and nitrogen purging facilities. The CD spectrum of $3 \mu \mathrm{M}$ DHc RNA, and $3 \mu \mathrm{M}$ DHc RNP (ratio of RNA: 7mC-Rev= 1:4) complex with dopamine $[1 \mathrm{mM}$ or $50 \mu \mathrm{M}$ (DHc 65)], norepinephrine [1 $\mathrm{mM}$ or $50 \mu \mathrm{M}(\mathrm{DHc} 65)]$ or epinephrine $[1 \mathrm{mM}$ or $50 \mu \mathrm{M}$ (DHc 65)] were measured in $50 \mathrm{mM}$ Tris- $\mathrm{HCl}(\mathrm{pH} \mathrm{7.6)}, 300 \mathrm{mM}$ $\mathrm{NaCl}, 5 \mathrm{mM} \mathrm{MgCl} 2,0.005 \%$ Tween 20 , and $0.02 \%$ ascorbic acid at $4{ }^{\circ} \mathrm{C}$. The data were gathered at the average of 10 time scans (scanning rate of $100 \mathrm{~nm} / \mathrm{min}$ ) from $320 \mathrm{~nm}$ to $190 \mathrm{~nm}$. The data were collected in units of millidegrees versus wavelength.

Acknowledgment. This work was supported in part by the Grants-in-Aid for Scientific Research from the Ministry of Education, Culture, Sports, Science and Technology, Japan to T.M. (No. 20241051).

Supporting Information Available: Thermodynamic parameters of fluorescent RNP to dopamine, norepinephrine and epinephrine at $4{ }^{\circ} \mathrm{C}$ (Table S1), possible secondary structures of DHc25 RNA, DHc58 RNA and DHc65 RNA obtained by mfold v3.0 algorithm. (Figure S1), saturation curves for the fluorescence emission intensity of fluorescent RNP to all ligands used in this study (Figure S2), the van't Hoff analysis (Figure S3) and CD spectra of the RNP complexes with catecholaminerelated ligands (Figure $\mathrm{S} 4$ ) were shown.

\section{Reference}

1. Johnsson, N.; Johnsson, K. ACS Chem. Biol. 2007, 2, 31-38.

2. Wang, H.; Nakata, E.; Hamachi, I. ChemBioChem 2009, 10, 2560-2577.

3. Tainaka, K.; Sakaguchi, R.; Hayashi, H.; Nakano, S.; Liew, F.F.; Morii, T. Sensor 2010, 1355-1376.

4. Zhang, J.; Campbell, R.E.; Ting, A.Y.; Tsien, R.Y. Nat. Rev. Mol. Cell Biol. 2002, 906-918.

5. Liu, J.; Cao, Z; Lu, Y. Chem. Rev. 2009, 109, 1948-1998.

6. Helinga, H.W.; Marvin, J.S. Trends Biotechnol. 1998, 16, 183189.

7. Tuerk, C.; Gold, L. Science 1990 249, 505-510.

8. Guo, K.T.; Paul, A.; Schichor, C.; Ziemer, G.; Wendel, H.P. Int. J. Mol. Sci. 2008, 9, 668-678. 
9. Sefah, K.; Shangguan, D.; Xiong, X.; O'Donoghue, M.B.; Tan, W. Nat. Protoc. 2010, 5, 1169-1185.

10. Ellington, A.D.; Szostak, J.W. Nature 1990, 346, 818-822.

11. Osborne, S.E.; Ellington, A. D. Chem.Rev. 1997, 97, 349-370.

12. Wilson, D.S.; Szostak, J.W. Аnпи. Rev. Biochem. 1999, 68, 611647.

13. Famulok, M.; Hartig, J.S.; Mayer, G. Chem. Rev. 2007, 107, 3715-3743.

14. Cho, E. J.; Lee, J.-W.; Ellington, A.D. Annu. Rev. Anal. Chem. 2009, 2, 241-264.

15. Hagihara, M.; Fukuda, M.; Hasegawa, T.; Morii, T. J. Am. Chem. Soc. 2006, 128, 12932-12940.

16. Hasegawa, T.; Hagihara, M.; Fukuda, M.; Morii, T. Nucleosides Nucleotides Nucleic acids 2007, 26, 1277-1281.

17. Battiste, J.L.; Mao, H.; Rao, N.S.; Tan, R.; Muhandiram, D. R.; Kay, L.E.; Frankel, A.D.; Williamson, J.R. Science 1996, 273, 1547-1551.

18. Sato, S.; Fukuda, M.; Hagihara, M.; Tanabe, Y.; Ohkubo, K.; Morii, T. J. Am. Chem. Soc. 2005, 127, 30-31.

19. Morii, T.; Hagihara, M.; Sato, S.; Makino, K. J. Am. Chem. Soc. 2002, 124, 4617-4622.

20. Fukuda, M.; Hayashi, H.; Hasegawa, T.; Morii, T. Trans. Mat. Res. Soc. Jpn. 2009, 34, 525-527.

21. Hasegawa, T.; Ohkubo, K.; Yoshikawa, S.; Morii, T. J. Surf. Sci. Nanotech. 2005, 3, 33-37.

22. Hasegawa, T.; Hagihara, M.; Fukuda, M.; Nakano, S.; Fujieda, N.; Morii, T. J. Am. Chem. Soc. 2008, 130, 8804-8812.

23. Sassanfar, M.; Szostak, J.W. Nature 1993, 364, 550-553.

24. Burke, D.H.; Gold, L. Nucleic Acids Res. 1997, 25, 2020-2024.

25. Weill, L.; Louis, D.; Sargueil, B. Nucleic Acids Res. 2004, 32, 5045-5058.

26. Nakano, S.; Mashima, T.; Matsugami, A.; Inoue, M.; Katahira, M.; Morii, T. J. Am. Chem. Soc. 2011, 133, 4567-4579.

27. Stoltenburg, R.; Reinemann, C.; Strehlitz, B. Biomol. Eng. 2007, 24, 381-403.

28. Björklund, A.; Dunnett, S.B. Trends Neurosci. 2007, 30, 194202.

29. Villoslada, P.; Oksenberg, J.R. Future Neurol. 2006, 1, 159-170.

30. Flatmark, T. Acta Physiol Scand 2000, 168, 1-17.
31. Mannironi, C.; Nardo, A.D.; Fruscoloni, P.; Tocchini-Valentini, G.P. Biochemistry 1997, 36, 9726-9734.

32. Walsh, R.; DeRosa, M. C. Biochem. Biophys. Res. Commun. 2009, 388, 732-735.

33. Jenison, R.D.; Gill, S.C.; Pardi, A.; Polisky, B. Science 1994, 263, $1425-1429$

34. Haller, A. A.; Sarnow, P. Proc. Natl. Acad. Sci. USA 1997, 94, 8521-8526

35. Zuker, M. Science 1989, 244, 48-52

36. Mathew, D.H.; Sabina, J.K.; Zuker, M.; Turner, D.H. J. Mol. Biol. 1999, 288, 911-940.

37. Zuker, M. Nucleic Acids Res. 2003, 31, 3406-3415.

38. Kumar, N.; Maiti, S. Biochem. Biophys. Res. Commun. 2004, 319, $759-767$.

39. André, C.; Xicluna, A.; Guillaume, Y. Electrophoresis 2005, 26, 3247-3255.

40. Lin, P.-H.; Yen, S.-L.; Lin, M.-S.; Chang, Y.; Lousi, S.R.; Higuchi, A.; Chen, W.-Y. J. Phys. Chem. B 2008, 112, 66656673.

41. Borea, P. A.; Dalpiaz, A.; Varani, K.; Gilli, K.; Gilli, G. Biochem. Pharmacol. 2000, 60, 1549-1556.

42. Shiroshi, M.; Yokota, A.; Tsumoto, K.; Kondo, H.; Nishimiya, Y.; Horii, K., Matsushima, M.; Ogasahara, K.; Yutani, K.; Kumagai, I. J. Biol. Chem. 2001, 276, 23042-23050.

43. Serin, G.; Joseph, G.; Ghisolfi, L.; Bauzan, M.; Erard, M.; Amalric, F.; Bouvet, P. J. Biol.Chem. 1997, 272, 13109-13116

44. Loret, E.P.; Georgel, P.; Johnson, W.C., Jr; Ho, P.S. Proc. Natl. Acad. Sci. USA 1992, 89, 9734-9738.

45. Karbstein, K.; Herschlag, D. Proc. Natl. Acad. Sci. USA 2003, 4, 2300-2305.

46. Drabovich, A. P.; Berezovski, M.; Okhonin, V.; Krylov, S. Anal. Chem. 2006, 78, 3171-3178

47. Zhou, H. Biophys. J. 2010, 98, L15-L17.

48. Gao, J.; Sidhu, S.; Wells, J.A. Proc. Natl. Acad. Sci. USA 2009, 106, 3071-3076.

49. Zahnd, C.; Sarkat, C.A.; Plückthun, A. Protein Eng. Des. Sel. 2010, 23, 175-184.

50. Chaires, J.B. Апnи. Rev. Biophys. 2008, 37, 135-151. 


\section{Supporting Information}

\section{Construction of Dopamine Sensors by Using Fluorescent Ribonucleopeptide Complexes}

Liew Fong Fong, ${ }^{\mathrm{a}}$ Tetsuya Hasegawa, ${ }^{\mathrm{a}}$ Masatora Fukuda, ${ }^{\mathrm{a}}$ Eiji Nakata, ${ }^{\mathrm{a}}$ and Takashi Morii ${ }^{\mathrm{a}, \mathrm{b} *}$ ${ }^{a}$ Institute of Advanced Energy, Kyoto University, Kyoto 611-0011, Japan

${ }^{b}$ CREST, JST, Uji, Kyoto 611-0011, Japan

*Corresponding author. Tel: +81 77438 3585; fax: +81 774383516

e-mail address: t-morii@iae.kyoto-u.ac.jp (T.M.) 
Table S1. Thermodynamic parameters of dopamine, norepinephrine and epinephrine binding to $\mathrm{DH} 05 / 7 \mathrm{mC}-\mathrm{Rev}$ at $4{ }^{\circ} \mathrm{C}$.

\begin{tabular}{lccc}
\hline Catecholamine & $\begin{array}{c}\Delta \mathrm{H} \\
\left(\mathrm{kcal} \mathrm{mol}^{-1}\right)\end{array}$ & $\begin{array}{c}-\mathrm{T} \Delta \mathrm{S} \\
\left(\mathrm{kcal} \mathrm{mol}^{-1}\right)\end{array}$ & $\begin{array}{c}\Delta \mathrm{G}_{4}{ }^{\circ} \mathrm{C} \\
\left(\mathrm{kcal} \mathrm{mol}^{-1}\right)\end{array}$ \\
\hline Dopamine & $-11.1 \pm 2.3$ & $4.7 \pm 2.3$ & $-6.4 \pm 0.1$ \\
Norepinephrine & $-9.9 \pm 0.4$ & $3.8 \pm 0.3$ & $-6.1 \pm 0.1$ \\
Epinephrine & $-8.5 \pm 1.0$ & $2.5 \pm 1.0$ & $-6.0 \pm 0.1$ \\
\hline
\end{tabular}

(a)

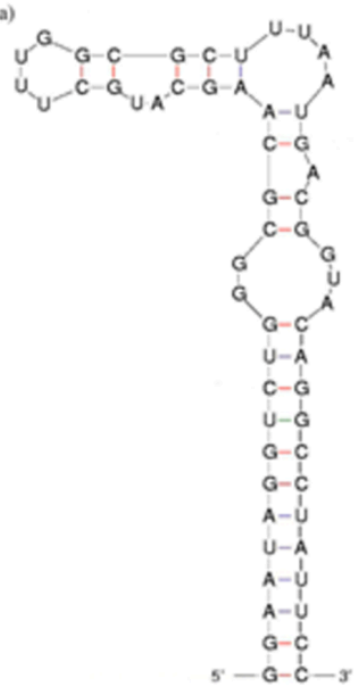

(b)
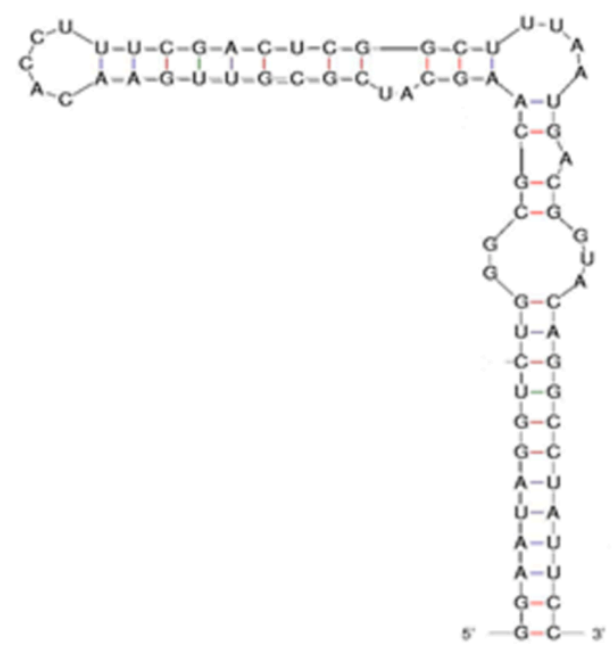

(c)

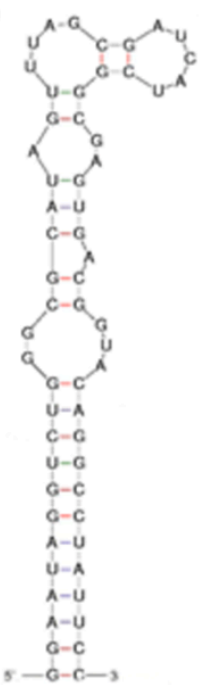

Figure S1. Possible secondary structures of (a) DHc25 RNA, (b) DHc58 RNA and (c) DHc65 RNA obtained by mfold v3.0 algorithm. 
(c)

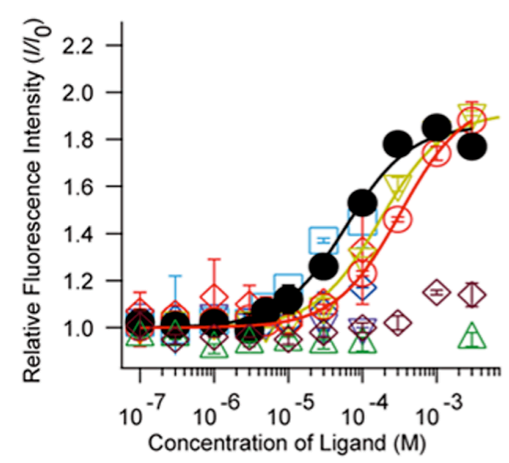

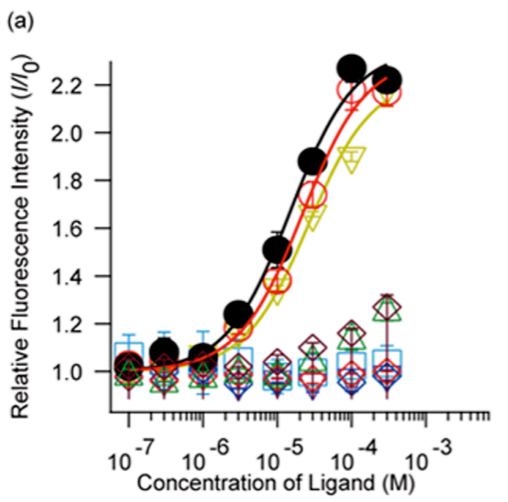

(d)

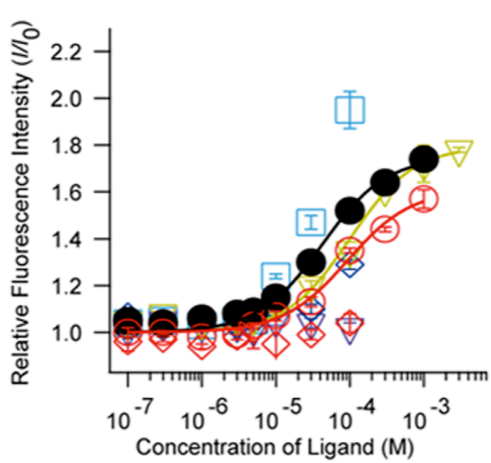

(b)

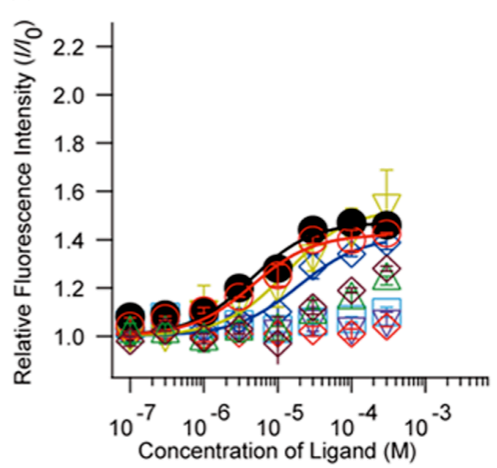

(e)

Figure S2. Saturation curves for the fluorescence emission intensity of (a) DL02/7mC-Rev, (b) DH05/7mC-Rev, (c) DHc25/7mC-Rev, (d) DHc58/7mC-Rev and (e) DHc65/7mC-Rev to dopamine (filled black circles), norepinephrine (open red circles), epinephrine (golden open reverse triangle), L-dopa (brown open diamonds), L-tyrosine (green open triangles), catechol (light blue open squares), tyramine (blue open diamonds), ethylamine (purple open reverse triangles), or phenyltylamine (red, open diamonds). 
(a)

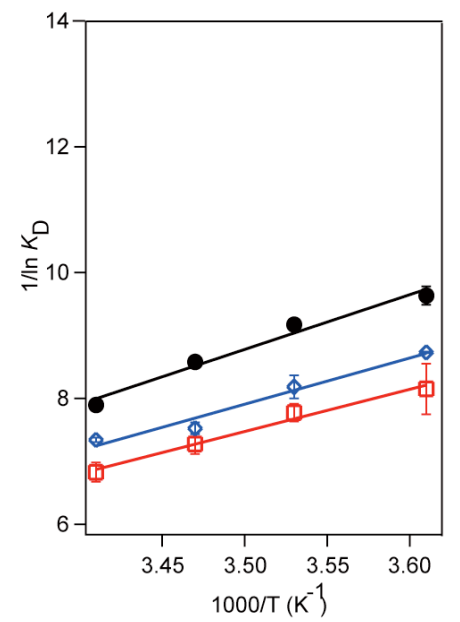

(b)

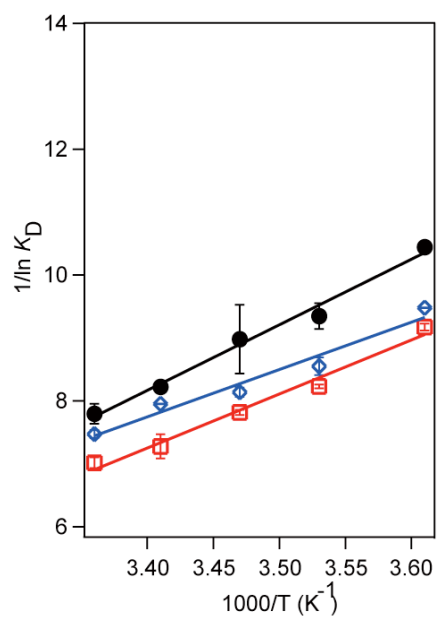

(c)

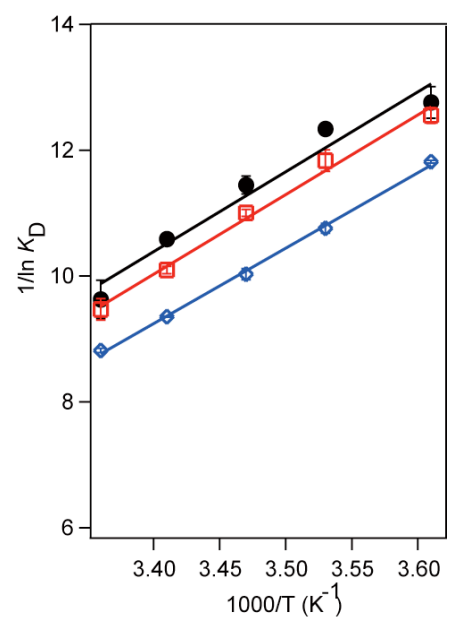

Figure S3. The van't Hoff analysis of (a) DHc25/7mC-Rev, (b) DHc58/7mC-Rev and (c) DHc65/7mC-Rev complexes with dopamine (black close circles), norepinephrine (red open squares) or epinephrine (blue open diamonds). Dissociation constants for the RNP-ligand complexes were obtained by titrations of fluorescence intensity changes at 277, 283, 288, 293 and $298 \mathrm{~K}$.

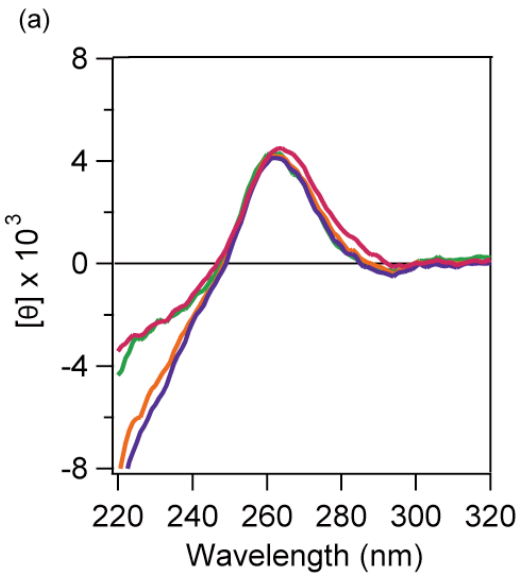

(b)

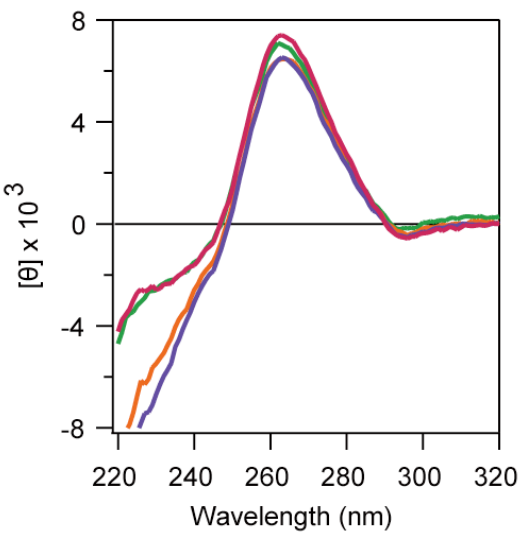

(c)

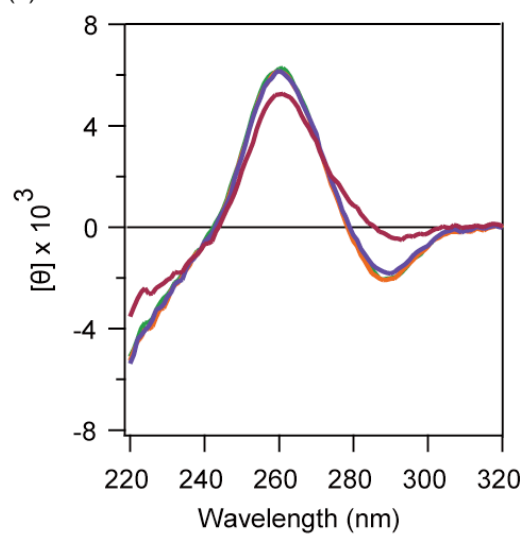

Figure S4. CD spectra of (a) DHc25, (b) DHc58 and (c) DHc65 with or without catecholamine. Spectra of RNP only (red line), RNP with dopamine (green line), norepinephrine (orange line) and epinephrine (purple line), respectively, were shown. 